\title{
Sistem Penjaminan Mutu Pendidikan Tinggi di Indonesia
}

\author{
Andi Arif Rifa'i \\ Fakultas Tarbiyah \\ IAIN Syaikh Abdurrahman Siddik Bangka Belitung, Indonesia \\ andiarifrifai@gmail.com
}

\begin{abstract}
Quality assurance is an important part of the higher education system which ensures that the effort to achieve quality is in accordance with the quality standards set by the government. The problem of the low quality of human resources of a nation is a manifestation of the inability of the quality assurance system to work effectively. Application of a model that is less effective in quality assurance, will have an impact on achieving the quality of Education. In Indonesia, various changes in the regulation of the quality assurance system began in 2006 - until now, basically both conceptually but not optimally in implementation. Internal and external quality assurance of higher education (HE) institutions has not produced satisfactory results, with the still low competitiveness of HE graduates and the competitiveness of the nation's human resources.
\end{abstract}

Keywords: Quality Assurance System, Quality of Education, Competitiveness

\begin{abstract}
Abstrak
Penjaminan mutu merupakan salah satu bagian penting dari system Pendidikan tinggi yang memastikan bahwa upaya pencapaian mutu sesuai standar mutu yang ditetapkan pemerintah. Problem rendahnya mutu SDM suatu bangsa merupakan wujud dari belum mampunya system penjaminan mutu bekerja secara efektif. Penerapan model yang kurang efektif dalam penjaminan mutu, maka akan berdampak pada pencapaian mutu Pendidikan. Di Indonesia, berbagai perubahan regulasi sistem penjaminan mutu Pendidikan tinggi dimulai sejak tahun 2006 - hingga sekarang, pada dasarnya baik secara konsep akan tetapi belum maksimal pada implementasinya. Penjaminan mutu internal dan eksternal perguruan tinggi belum memberikan hasil yang memuaskan, dengan masih rendahnya daya saing lulusan perguruan tinggi serta daya saing SDM Bangsa
\end{abstract}

Kata kunci: Sistem Penjaminan Mutu, Mutu Pendidikan, Daya Saing 


\section{A. Pendahuluan}

Dunia pada saat ini telah memasuki era baru yakni globalisasi, yang menuntut setiap negara atau bangsa untuk mempersiapkan diri guna menghadapi persaingan antar bangsa. Perdagangan bebas merupakan wujud nyata produk dari globalisasi. Tanpa sumber daya manusia yang berkualitas niscaya kita tidak akan mampu bersaing dengan negara-negara lain di dunia. Kualitas sumber daya manusia (SDM) hanya dapat diwujudkan melalui pendidikan yang berkualitas. Penyelenggaraan pendidikan mulai dari pendidikan dasar, menengah dan tinggi harus terjamin mutunya guna mendukung percepatan peningkatan mutu SDM bangsa.

Pendidikan tinggi sebagai salah satu faktor penting dalam menciptakan Sumber Daya Manusia yang berkualitas dan berdaya saing tinggi. Kemampuan perguruan tinggi menghasilkan lulusan berkualitas secara tidak langsung akan meningkatkan daya saing bangsa dalam persaingan antar bangsa. Pemerintah Indonesia sejak tahun 1986 telah memulai upaya pengembangan SDM dengan melakukan reformasi mendasar dalam bidang Pendidikan Tinggi melalui berbagai program, salah satunya penjaminan mutu (quality assurance).

Program penjaminan mutu perguruan tinggi tertuang dalam Strategi Jangka Panjang Pendidikan Tinggi Indonesia 2003-2010 (HELTS/ Higher Education Long Term Strategy 2003-2010) dengan tiga fokus reformasi yaitu: (1) mutu sebagai inti untuk membangun daya saing bangsa; (2) pengelolaan otonomi dan (3) kesehatan organisasi. Fokus reformasi tersebut dijelaskan pada Bagian II Bab III poin E HELTS 2003-2010 secara lebih rinci dijelaskan bahwa: dalam sebuah organisasi yang sehat peningkatan mutu berkelanjutan (continuous quality improvement) harus menjadi perhatian utama. Oleh sebab itu, maka penjaminan mutu harus didorong secara internal, dilembagakan dalam standar prosedur masing-masing perguruan tinggi (PT), dan juga bisa melibatkan pihak eksternal. Oleh karena mutu pendidikan juga menjadi perhatian dari semua pemangku kepentingan (stakeholder PT), maka peningkatan mutu (quality improvement) harus bertujuan untuk menghasilkan output dan outcome sebagai bagian dari akuntabilitas publik. ${ }^{1}$

\footnotetext{
${ }^{1}$ Ikhfan Haris. 2013. Assessment on The Implementation of Internal Quality Assurance at Higher Education (An Indonesian Report). Journal Of Educational And Instructional Studies In The World, November 2013, Volume: 3 Issue: 4 Article: 06 Issn: 2146-7463 (P. 41-50). p.41-42
} 
Mutu lulusan (output) membutuhkan komitmen dan kesadaran dari setiap perguruan tinggi sebagai penyelenggaraan Pendidikan tinggi. Kesadaran akan pentingnya mutu sudah sejak lama tumbuh dan berkembang di berbagai negara. Di amerika Serikat misalnya, sebagaimana diungkapkan oleh freeman (dalam Becker, 1993: 17), pada tahun 1970-an para ekonom khawatir terkait “overeducated american's”, sehingga memunculkan perbincangan serius diantara mereka. Namun, kondisi tersebut tidak berjalan lama, kencenderungan perbincangan mereka berubah menjadi apakah United State (US) menyiapkan atau menyediakan kualitas dan kuantitas yang memadai dari penyelenggaraan pendidikan yang ada. Bonus demografi dari manusia terdidik (over educated American's) disadari mereka akan menjadi daya saing dalam menghadapi persaingan global antar bangsa di dunia sehingga invesatsi dalam pendidikan menjadi faktor penting dan mutu layanan pendidikan menjadi prasyarat utamanya. ${ }^{2}$ Lebih lanjut L. Golobert (dalam Liu LiHong, 2008: 5) menjelaskan bahwa sejak pertengahan tahun 1990-an, kebangkitan Quality Assurance di Perguruan Tinggi telah berlangsung di negara-negara di seluruh dunia. Quality control, quality assurance dan Total Quality Management (TQM) telah menjadi topik utama di Perguruan Tinggi. Dimana topic yang diperbincangkan pada tahun 1980 adalah terkait efisiensi, sedangkan pada tahun 1990 lebih kepada kualitas. ${ }^{3}$

Joannes (2012: 28) dalam paparenya yang berjudul Internal quality management and organisational values in higher education Conceptions and perceptions of teaching staff menyatakan bahwa pada abad kedua puluh, manajemen mutu berkembang dalam tahapan proses aditif tumpang tindih. Tahap pertama adalah 'pemeriksaan mutu' dengan fokus pada produk, melacak cacat selama dan setelah proses manufaktur dan metode statistik untuk mengukur dan menentukan batas toleransi. Tahap kedua berfokus pada 'kualitas teknik' atau 'quality control' dan berkonsentrasi pada desain produk atau jasa, berdasarkan daftar spesifikasi dan persyaratan untuk menghindari atau meminimalkan cacat. Tahap ketiga berfokus pada 'jaminan mutu' (quality assurance) dan proses bekerja dengan lebih mempertimbangkan aspek motivasi kerja, seperti komunikasi, organisasi dan pelatihan, dan faktor-faktor input dan persyaratan material. Dalam hal ini Industri dan

${ }^{2}$ Gary S. Becker. 1993. Human Capital A Theoretical and Empirical Analysis with Special Rference to Education Third Edition. The University of Chicago Press: Chicago London. p.17

${ }^{3}$ Liu LiHong, 2008, QUALITY ASSURANCE : Internal Strategies in US Higher Education Institutions - A Case Study at the University of Nebraska - Lincoln, National Academy of Education Administration Beijing, P.R. China. p.5 
organisasi sadar akan pentingnya harapan pelanggan dan menekankan pentingnya dokumentasi, standar dan audit. ${ }^{4}$

Berdasarkan prinsip-prinsip gerakan kualitas dalam abad kedua puluh di atas, kualitas dijelaskan dalam tujuh cara yang berbeda, pertama berorientasi pada produk atau hasil: 1) Kualitas merupakan entitas apodiktis dan universal, yang hampir-hampir tidak mungkin untuk menentukan tetapi memiliki orisinalitas, keunikan dan upaya investasi sebagai bahan vital; 2) Kualitas sesuai dengan seperangkat standar minimum; 3) Kualitas adalah keunggulan, berdasarkan standar tinggi yang harus dilampaui; 4) Kualitas adalah kesempurnaan (zero defect). ${ }^{5}$

Berbagai perkembangan konsep tentang pengembangan mutu di atas, menyadarkan akan pentingnya penjaminan mutu pendidikan. Penjaminan mutu pendidikan tinggi di Indonesia secara praksis dilakukan melalui tiga bentuk yaitu penjaminan mutu internal, penjaminan mutu eksternal oleh BAN-PT (Badan Akreditasi Perguruan Tinggi), dan perizinan program studi. Yang menjadi pertanyaan sekarang adalah apakah penjaminan mutu dalam tiga bentuk tersebut efektif menjamin mutu lulusan atau keluaran perguruan tinggi di Indonesia?. Persoalan tersebut akan diurai dalam bahasan selanjutnya.

\section{B. Indonesia Telah Lama Menghadapi Problem Mutu}

Paul Suparno SJ (dalam Sukarjo, 2009:79) melakukan analisa dan berujung pada perumpamaan pada kondisi pendidikan Indonesia tak ubahnya seperti sebuah mobil tua dengan kondisi mesin bermasalah, yang sedang berada di tengah arus lalu lintas pada jalur bebas hambatan. Kondisi pendidikan Indonesia menghadapi tiga masalah besar, yaitu: (1) mutu pendidikan yang masih rendah, (2) sistem pembelajaran yang masih belum memadai, dan (3) krisis moral yang melanda masyarakat. Sejalan dengan analisis tersebut, Bahrul Hayat menyebut kondisi pendidikan indonesia saat ini sedang menghadapi problematik paradoks di alam globalisasi: dimana di satu sisi harus membangun mutu pendidikan (the pursuit of excellence) sesuai dengan rujukan-mutu (banchmarking) kompetensi global agar tidak tersisih dari persaingan antar bangsa, sedangkan di sisi lain dituntut menimbang mutu

\footnotetext{
${ }^{4}$ Joannes Chrysostomus Bernardus Marie Kleijnen. 2012. Internal quality management and organisational values in higher education Conceptions and perceptions of teaching staff. Jan Kleijnen, Maastricht 2012 Production: Datawyse | Universitaire Pers Maastricht. p.28

${ }^{5}$ Joannes Chrysostomus Bernardus Marie Kleijnen. 2012. Internal quality management and organisational values in higher education Conceptions and perceptions of teaching staff. Jan Kleijnen, Maastricht 2012 Production: Datawyse | Universitaire Pers Maastricht. p.26
} 
dalam keragaman dan kearifan lokal agar siswa hidup dengan menapak di bumi sendiri (Bahrul hayat, 2010:3). Persoalan mutu menjadi kian pelik diperparah dengan praktik pendidikan kita yang belum menemukan titik kulminasinya sebagai sebuah lembaga bermutu tinggi.

Berdasarkan data hasil survei Human Development Index (HDI) pada tahun 2005 yang dilakukan United Nation Development Program (UNDP) menempatkan Indonesia pada peringkat 113 dari 177 negara didunia. Rendahnya sumber daya manusia Indonesia berdasarkan hasil survei UNDP tersebut secara tidak langsung dapat mencerminkan rendahnya mutu pendidikan Indonesia, sebab pendidikan secara langsung bersentuhan dengan penciptaan SDM Bangsa. Problematikan mutu SDM bangsa mengandung makna terdapat problematika penyelenggaraan pendidikan tinggi yang belum mampu terselesaikan.

Persoalan mutu pendidikan tinggi di Indonesia menjadi kian rumit dihadapkan pada institusi penyelenggara yang beragam. Adapun ragam perguruan tinggi di bagi dalam tiga bentuk, pertama; PTN (Perguruan Tinggi Negeri) dan PTS (Perguruan Tinggi Swasta), kedua; PTA (Perguruan Tinggi Agama) yang berada di bawah Kementerian Agama dan PTU (Perguruan Tinggi Umum) yang berada di bawah Kementerian Pendidikan dan Kebudayaan), dan ketiga; Sekolah Tinggi, Institut dan Universitas. Untuk mengatur dan memastikan penyelenggaraan pendidikan tinggi yang bermutu, Pemerintah melalui Undang-Undang Sistem Pendidikan Nasional (UUSPN) nomor 20 tahun 2003 Pasal 51 ayat 2 secara tegas mengamanatkan bahwa pengelolaan satuan pendidikan tinggi harus dilaksanakan berdasarkan 4 prinsip utama; otonomi, akuntabilitas, jaminan mutu dan evaluasi yang transparan. Artinya setiap perguruan tinggi wajib menjalanlan jaminan mutu yang mampu memastikan terwujudnya SDM bangsa berkualitas.

Sistem penjaminan mutu di Indonesia terdiri atas perizinan prodi (SPM-PT 2016) PDPT (SPM-PT 2020), penjaminan mutu internal (SPMI/Sistem Penjaminan Mutu Internal), dan penjaminan mutu eksternal (BAN-PT). Artinya sebuah PT yang tidak melakukan jaminan mutu dengan melakukan tiga kegiatan tersebut tidak dapat menyelenggarakan Pendidikan tinggi secara berkualitas. Problem mendasar yang menjadi pertanyaan disini adalah apakah ketiga unsur tersbut telah berjalan dengan baik dan saling mendukung satu sama lain? 


\section{Penjaminan Mutu Perguruan Tinggi: Konsep dan Model \\ 1. Makna Mutu}

Sebelum mengkaji penjaminan mutu perlu dipahami terlebih dahulu makna kata mut. Terdapat tiga pandangan terkait dengan mutu, yaitu produk, layanan dan harapan konsumen (Peter dalam Sallis, 2012:19). ${ }^{6}$ Ketiga konsep tersebut mendasari arah pemaknaan mutu dari berbagai pakar. Mutu produk dalam pendidikan sering mengacu pada ukuran keluaran pendidikan (educational outcomes). Sedangkan mutu layanan mengacu pada ukuran layanan dalam pendidikan. Mutu dari sisi konsumen dapat dimaknai sebagai kesesuaian dengan yang dipersyaratkan (conformance to requirement) harapan konsumen pendidikan.

An attempt to eliminate the inadequacies of quality control gave birth to other terminologies such as total quality management or quality assurance. Quality assurance is seen as a proactive approach to production processes in the manufacturing sector. The origin of quality assurance can be traced to two Americans (W. Edwards Derming, Joseph Juran) and a Japanese (Ishikawa) who were identified as exercising the greatest influences on the total quality approach to management. (Cole, 1996 cited in Babalola and Ayeni (2009:762). ${ }^{7}$

Adapun pendapat para ahli juga berbeda terkait definisi mutu, diantaranya; Menurut Juran (1993), mutu produk adalah kecocokan penggunaan produk (fitness for use) untuk memenuhi kebutuhan dan kepuasan pelanggan. Kecocokan pengguna produk tersebut didasarkan atas lima ciri utama yaitu (1) teknologi; yaitu kekuatan; (2) psikologis, yaitu rasa atau status; (3) waktu, yaitu kehandalan; (4) kontraktual, yaitu ada jaminan; (5) etika, yaitu sopan santun.

Sedangkan Menurut Crosby (1979:58), mutu adalah conformance to requirement, yaitu sesuai dengan yang disyaratkan atau distandarkan. Suatu produk memiliki mutu apabila sesuai dengan standar atau kriteria mutu yang telah ditentukan. Standar mutu tersebut meliputi bahan baku, proses produksi, dan produk jadi. Menurut Deming (1982:176), mutu adalah kesesuaian dengan kebutuhan pasar atau konsumen. Perusahaan yang bermutu adalah perusahaan yang menguasai pangsa pasar karena hasil produksinya

\footnotetext{
${ }^{6}$ Edward Sallis. Alih Bahasa Ali riyadi, Ahmad \& Fahrurozi. 2006. Total Quality Management in Education: Manajemen Mutu Pendidikan. Yogyakarta. p.19

${ }^{7}$ Florence Imaobong Archibong. Instructional Supervision In The Administration of Secondary Education: A Panacea For Quality Assurance. European Scientific Journal, June Edition Vol. 8, No.13, ISSN: 1857 - 7881 (Print) E - ISSN 1857- 7431. p-64
} 
sesuai dengan kebutuhan konsumen, sehingga menimbulkan kepuasan bagi konsumen. Jika konsumen merasa puas, maka mereka akan setia dalam membeli produk perusahaan baik berupa barang maupun jasa.

Harvey dan Stensaker (2008) menyajikan lima cara yang berbeda untuk mendefinisikan kualitas demikian :

1. Kualitas sebagai luar biasa (Quality as exceptional). Di sini kualitas terkait dengan keunggulan dan biasanya dioperasionalkan sebagai standar yang sangat tinggi dari prestasi akademik . Kualitas dicapai jika standar yang disyaratkan atau melampaui .

2. Kualitas sebagai kesempurnaan atau konsistensi (Quality as perfection or consistency). Dalam definisi ini, kualitas berarti tanpa cacat dan mendapatkan halhal yang benar pada kali pertama . Kualitas dalam pengertian ini diasumsikan tidak berlaku untuk situasi belajar kecuali di wilayah konsistensi penghakiman akademik dan keandalan informasi manajemen.

3. Kualitas sebagai kesesuaian untuk tujuan (Quality as fitness for purpose). Di sini kualitas dinilai oleh sejauh mana itu memenuhi tujuan tertentu . Hal ini terkait dengan kebutuhan pelanggan dan kepuasan.

4. Kualitas sebagai nilai untuk uang (Quality as value for money). Kualitas dinilai melalui pengembalian investasi . Gagasan akuntabilitas dalam pendidikan dibawa ke fokus dalam definisi ini.

Dalam dunia pendidikan, kualitas dipahami sebagai transformasi (Quality as transformation). Artinya kualitas dipandang sebagai suatu proses perubahan. Proses pendidikan dipahami sebagai proses transformasi yang mengarah ke perubahan kualitatif peserta didik menuju pada peningkatan dan pemberdayaan mereka. ${ }^{8}$

Dalam konsep Penjaminan Mutu Perguruan Tinggi yang menjadi tujuan utamanya adalah tumbuh budaya mutu (quality culture) mulai dari; bagaimana menetapkan standar, melaksanakan standar, mengevaluasi pelaksanaan standar dan secara berkelanjutan

${ }^{8}$ Florence Imaobong Archibong. Instructional Supervision In The Administration Of Secondary Education: A Panacea For Quality Assurance. European Scientific Journal, June Edition Vol. 8, No.13 2013, ISSN: 1857 - 7881 (Print) E - ISSN 1857- 7431. p-173 
berupaya meningkatkan standar (Continuous Quality Improvement). ${ }^{9}$ Penjaminan Mutu Perguruan Tinggi di Indonesia merupakan konsep multi stakeholders; Masyarakat, Direktorat Jenderal Pendidikan Tinggi, dan institusi pendidikan tinggi. Penjaminan mutu Perguruan Tinggi (PT) Berdasarkan SPM-PT 2006, Sistem penjaminan mutu perguruan tinggi dilakukan atas dasar penjaminan mutu internal, penjaminan mutu eksternal, dan perijinan penyelenggaraan program. ${ }^{10}$

2. Model Penjaminan Mutu di Perguruan Tinggi

Adapun model penjaminan mutu yang berkembang di perguruan tinggi polanya adalah sebagai berikut:

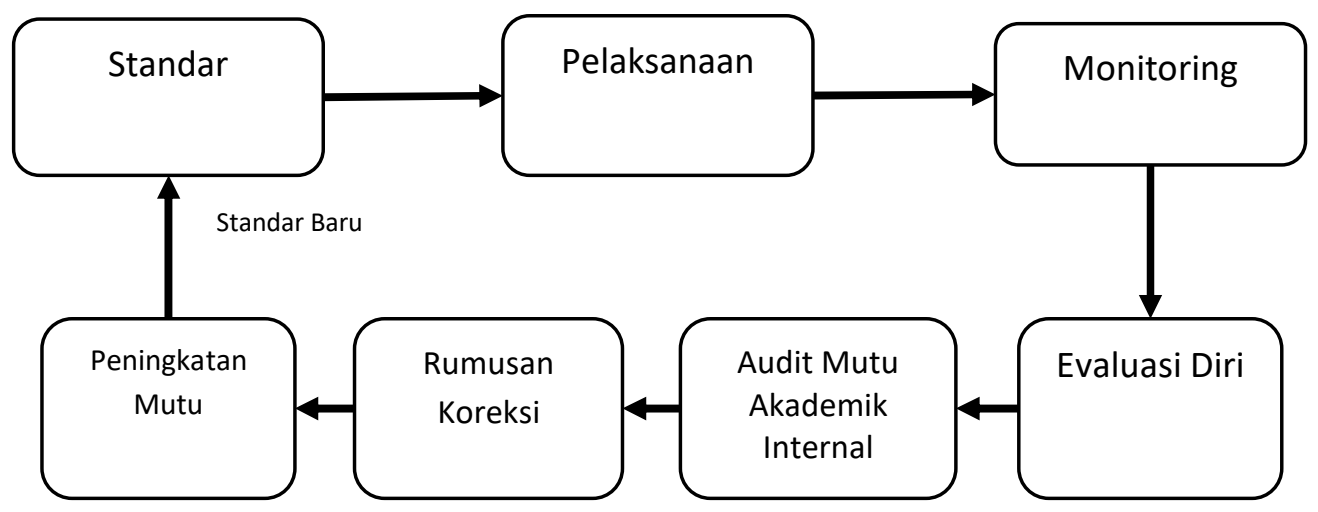

Bagan 1. Model Sistem Penjaminan Mutu PT

Standar dan pedoman penjaminan mutu pada Perguruan Tinggi Eropa dikembangkan oleh ENQA,EUA, EURASHE, dan ESIB, dan diadopsi oleh European Minister reponsible for Higher Education pada konferensi Bergen 2005. Pendekatan terhadap kualitas merupakan integrasi dari elemen-elemen berikut:

a. Menjamin realisasi dari standar dan benchmarks minimal

b. Kapasistas untuk membuat tujuan didalam konteks yang berbeda dan untuk mencapainya dengan input dan konteks variabel yang ada.

c. Kemampuan untuk memuaskan permintaan dan harapan (ekspektasi) dari pelanggan dan stakeholder langsung maupun tidak langsung.

d. Menuju kesempurnaan (Dirk 2003)

\footnotetext{
${ }^{9}$ Direktorat Jenderal Pendidikan Tinggi Departemen Pendidikan Nasional, 2006. Panduan Pelaksanaan Sistem Penjaminan Mutu Perguruan Tinggi (SPM-PT), p.iii

${ }^{10}$ Direktorat Jenderal Pendidikan Tinggi Departemen Pendidikan Nasional, 2006. Panduan Pelaksanaan Sistem Penjaminan Mutu Perguruan Tinggi (SPM-PT), p.4
} 
Penjaminan mutu di perguruan tinggi khususnya di negara Inggris (United Kingdom/UK) berbasis pada:

a. Framework untuk kualifikasi pendidikan tinggi, subject benchmark statement dan a sector - wide code dari praktek untuk penjaminan mutu akademik dan standar dalam pendidikan tinggi.

b. Review eksternal independen dari beberapa universitas oleh Quality Assurance Agency for Higher Education (QAA), menghasilkan laporan yang dipublikasikan; publikasi QAA hanya berupa laporan berbasis pada materi review eksternal

c. Perjanjian efektif dengan murid-murid dan pekerja-pekerja, termasuk profesional, kumpulan peraturan dan perundang-undangan, yangmana membantu untuk menentukan apa yang harus universitas lakukan.

d. Survey siswa nasional yang memberikan informasi pada universitas dan masyarakat terkait cara pandang siswa terkait pengalaman universitas mereka, termasuk kepuasan mereka.

e. Akademi Pendidikan Tinggi yang didukung profesionalisme dalam mengajar melalui pengembangan profesional, framework standar UK, dan skema beasiswa.

Pada tahun 1971 di Amerika Serikat, Stufflebeam mengidentifikasi empat domain tertentu membantu dalam mengevaluasi program pendidikan dan sosial: Context, Input, Process and Product (CIPP). Konteks meliputi: pengaturan sosial lembaga; karakteristik siswa; sejarah sebelumnya, dan budaya internal dan eksternal perguruan tinggi dan universitas; parameter yang ditetapkan oleh lembaga independen atau undang-undang dan peraturan pemerintah; dan aspirasi formal untuk tingkat yang lebih tinggi dari inklusi sosial dan partisipasi . Input meliputi: keuangan, sumber daya fisik dan elektronik; tingkat entri siswa; rasio guru / siswa; kualifikasi akademisi dan pengetahuan materi pelajaran mereka; dan gelar dan struktur program. Proses meliputi kegiatan mengajar yang sebenarnya, yaitu, kinerja (kompetensi) guru; partisipasi siswa dan keterlibatan; online, kampus berbasis dan bentuk-bentuk interaksi; praktek etis; dan metode penilaian dan keputusan grading. Produk (hasil) termasuk tingkat retensi, kemajuan, wisuda, dan 
gesekan; kerja; mulai gaji pada saat masuk ke dunia kerja; dan mahasiswa dan kepuasan kerja. $^{11}$

3. Internal Quality Assurance Perguruan Tinggi (PT)

Penjaminan mutu (quality assurance) merupakan proses kolektif yang dilakukan universitas sebagai sebuah jaminan instituasi akademik yang menjaga kualitas proses pendidikan sesuai standar yang ditetapkan sendiri. ${ }^{12}$ Lebih lanjut, termasuk dalam definisi ini beberapa dimensi kunci dari penjaminan mutu pada pendidikan tinggi:

a. Penjaminan mutu fokus pada proses; ini bertujuan untuk meyakinkan konstituen internal dan eksternal bahwa institusi melakukan proses yang menghasilkan outcome berkualitas tinggi.

b. Penjaminan mutu membuat akuntabilitas yang tegas (jelas) untuk kualitas pada berbagai poin dalam institusi, kualitas adalah tanggungjawab setiap orang dalam organisasi.

c. Penjaminan mutu merupakan proses berlanjut, aktif, dan responsif yang termasuk didalamnya evaluasi dan balikan yang kuat. Komunikasi efectif adalah penting untuk kesuksesan sistem penjaminan mutu.

Pada dasarnya, ada tiga tujuan utama di balik penilaian Pelaksanaan penjaminan mutu internal pada pendidikan tinggi di Indonesia. Alasan-alasan ini adalah sebagai berikut:

a. Menilai apa memperpanjang pelaksanaan penjaminan mutu internal perguruan tinggi.

b. Menyajikan profil kualitas setiap lembaga belajar di universitas atau pendidikan tinggi di bawah program penjaminan mutu internal. Maksud di balik profil ini adalah untuk mengekspos kekuatan dan kelemahan lembaga ini pada program jaminan kualitas itu.

c. Program ini juga bertujuan untuk memberikan umpan balik, saran dan rekomendasi kepada perguruan tinggi yang telah menerapkan penjaminan mutu

${ }^{11}$ D. Royce Sadler. Assessment, Evaluation And Quality Assurance: Implications For Integrity In Reporting Academic Achievement In Higher Education. Education Inquiry Vol. 3, No. 2, June 2012, p.204

${ }^{12}$ Andreawilger. 1997. Quality Assurance In Higher Education: A Literature Review. National Center For Postsecondary Improvement 508 Ceras School Of Education Stanford University, Stanford, Ca 94305-3084. p.2 
internal. Ini akan memiliki lembaga untuk meningkatkan, mengembangkan dan juga untuk meluruskan pelaksanaan penjaminan mutu internal di lembaga mereka (Haris, 2013: 41-42). ${ }^{13}$

Sistem penjaminan mutu yang efektif didasarkan pada beberapa asumsi: (1) bahwa institusi memiliki misi dan tujuan yang jelas didefinisikan, (2) bawha misi dan tujuan institusi secara luas dikamunikasikan dan difahamkan terhadap organisasi. (3) Bahwa institusi menjelaskan kualitas dengan jeals sesuai dengan konteks dari misi dan tujuannya. Dan (4) Bahwa instituasi memiliki jaringan komunikasi yang kuat. ${ }^{14}$

Bagaimana guru dalam pendidikan tinggi (dosen) mempromosikan belajar ? Sejumlah besar peneliti telah meneliti hal ini sejak 1970-an, menjadi contoh Biggs \& Tang (2007), Elton ( 1998), Ramsden (1991 , 2003), Sherman et al (1987) dan Skelton (2005). Dalam berbagai cara, mereka semua berusaha untuk mengidentifikasi dimensi penting atau aspek keunggulan mengajar. Seperti yang diharapkan, temuan telah jauh tumpang tindih. Contohnya antara lain: memiliki tujuan yang jelas; yang dipersiapkan dengan baik dan terorganisir; mengetahui materi pelajaran secara menyeluruh; terampil berkomunikasi; tepat menggunakan informasi dan teknologi komunikasi; rangkaian materi dan mengelola waktu; pengajaran dan pengujian untuk hasil kognitif tingkat tinggi ; membangun empati dengan siswa; tujuan penyelarasan, mengajar dan penilaian; aktif melibatkan siswa; merancang untuk mengajar penelitian yang dipimpin; memberikan umpan balik berkualitas baik segera; dan responsif terhadap evaluasi siswa mengajar. ${ }^{15}$

Adapun Ruang lingkup jaminan kualitas sebagai termasuk dimensi sebagai berikut:

a. Peraturan (kerangka hukum, tata kelola, akuntabilitas dan tanggung jawab dll)

${ }^{13}$ Ikhfan Haris. 2013. Assessment on The Implementation of Internal Quality Assurance at Higher Education (An Indonesian Report). Journal Of Educational And Instructional Studies In The World, November 2013, Volume: 3 Issue: 4 Article: 06 Issn: 2146-7463 (P. 41-50). p.3

${ }^{14}$ Andreawilger. 1997. Quality Assurance In Higher Education: A Literature Review. National Center For Postsecondary Improvement 508 Ceras School Of Education Stanford University, Stanford, Ca 94305-3084. p.3

${ }^{15}$ D. Royce Sadler. Assessment, Evaluation And Quality Assurance: Implications For Integrity In Reporting Academic Achievement In Higher Education. Education Inquiry Vol. 3, No. 2, June 2012, p.204-205 
b. Proses Pendidikan (penerimaan, registrasi atau pendaftaran, desain kurikulum dan pengiriman, dukungan untuk meninggalkan, penilaian dll)

c. desain Kurikulum dan konten (validasi dan persetujuan kerangka kerja, tingkat dan standar dll).

d. Pengalaman Belajar (perlindungan konsumen, pengalaman siswa, keluhan dan banding dll).

e. Hasil (kualifikasi, sertifikat, transkrip, keamanan, transferabilitas, pengakuan. ${ }^{16}$

\section{Penjaminan Mutu dalam mengembangkan Budaya Mutu}

1. Budaya Mutu PT

Berdasarkan dengan tujuan dari pada penjaminan mutu Perguruan Tinggi di atas maka budaya mutu (quality culture) merupakan syarat untuk continuous quality improvement dalam membentuk outcome yang berkualitas. Secara etimologi makna budaya adalah pola dari susunan, materi atau perilaku yang diadopsi oleh sebuah masyarakat, perusahaan (corporasi), kelompok atau team (Wan Yusoff, et al, 2006:2). Dengan demikian, budaya merupakan pola perilaku yang dijadikan norma pada sebuah komunitas. Jika dikaitkan dengan guru, maka budaya tersebut diadopsi oleh kelompok guru (teachers community) sebagai sebuah nilai bersama atau kesadaran bersama atas mutu.

Sedangkan kualitas (quality) memiliki makna yang subyektif, dimana setiap orang atau sektor memiliki pemaknaan yang berbeda-beda. Dapat dikatakan sebagai sebuah konsep yang selalu memiliki subjek pada konteks sejarah, ekonomi, nasional dan internasional (Inga Milisiunaite et al, 2009:4). Dalam dunia industri manufaktur dan sektor layanan konsep mutu (quality) dimaknasi sebagai; kepuasan pelanggan, kemampuan untuk digunakan, dan penyesuaian diri pada kebutuhan (Inga Milisiunaite et al, 2009:4). Sedangkan dalam perspektif budaya mutu (quality culture) sendiri, kualitas lebih dilihat sebagai nilai-nilai dan praktek-praktek (Vettori, et al. 2007).

\footnotetext{
${ }^{16}$ Andreawilger. 1997. Quality Assurance In Higher Education: A Literature Review. National Center For Postsecondary Improvement 508 Ceras School Of Education Stanford University, Stanford, Ca 94305-3084. p.173
} 
Secara epistimologi budaya mutu merupakan sebuah konsep, yang berhubungan dengan suasana dari unjuk kerja tugas dengan melihat pada prestasi terbaik pencapaian tujuan. ${ }^{17}$ Lebih lanjut Brings (2010) mengatakan bahwa didalam budaya mutu terdapat nilai, keyakinan, sikap, komitmen, ekspektasi, kesepakatan (agreement), kapasitas, negosiasi, partisipasi, persatuan (unity)_dan kepercayaan. ${ }^{18}$

Budaya mutu dalam konteks pendidikan, sebagaimana hasil riset yang dilakukan oleh Isara Tongsamsi dkk (2009:16) terhadap faktor-faktor yang berpengaruh pada budaya mutu dari 60 institusi PTN sebagai sampelnya, menghasilkan konstruksi ; buaya mutu secara langsung dipengaruhi oleh komitmen terhadap mutu (comitment to quality), persepsi pada level managerial dan kepercayaan pada hasil penilaian mutu pendidikan (trust in the education quality asessment result). Komitmen pada mutu sendiri dipengaruhi oleh kepercayaan pada hasil penilaian mutu pendidikan, komunikasi terkait penilaian mutu pendidikan (pengaruhnya rendah), dan partisipasi dalam penilaian mutu pendidikan. Secara garis besar, budaya mutu tidak berdiri sendiri, akan tetapi didukung (dipengaruhi) oleh faktor lain yang terkait dengannya.

2. Faktor-faktor yang mempengaruhi Budaya Mutu PT

Berdasarkan pada kajian di atas, bahwasannya budaya mutu dipengaruhi oleh faktor-faktor yang menjadi penentu terciptanya sebuah bangunan quality culture, maka langkah-langkah pengembangannya tidak dapat dicerabut dari faktor-faktor tersebut. Misalnya, dalam membangun budaya mutu maupun mengembangkan mutu secara berkelanjutan (Continuous Quality Culture Improvement), yang menjadi fokus garapan dalam dunia industri antara lain; Leadership and Top Management Commitment, Customer Management, Training and Education, Teamwork, People Management and Empowerment, Supplier Partnership, Quality Policy and Strategy, Process Management, Rewards and Recognition dan Effective Communication (Wan Yusoff, et al, 2006:4-7).

\footnotetext{
${ }^{17}$ Harpal Singh Yadav, Quality culture in Teacher Education. International Indexed \& Refferred Research Journal, ISSN-2250-2599; Vol. I* ISSUE -1 Oct., 2012. p.55

${ }^{18}$ IsaraTongsamsi, Akom Chaikeaw, Chidchanok Churngchow, \& Thoedtida Thipparat, A Structural Equation Model of Factors Influencing the Quality Culture of the Workforce in Thailand Public Higher Education Institutions, International Journal of Education ISSN 1948-5476 2012, Vol. 4, No. 4, www.macrothink.org/ije. 17
} 
Dalam dunia pendidikan, jika dilihat dari standar dan pedoman penjaminan mutu pada perguruan tinggi di Eropa, yang menjadi wilayah pengembangan adalah; konsep budaya mutu (quality culture concept), prinsip-prinsip utama manajemen mutu, teori organisasi pembelajaran, dan prinsip-prinsip sistem informasi manajemen. ${ }^{19}$ Secara nyata, konsep terkait pengembangan budaya mutu merupakan satu hal terpenting dalam dunia pendidikan yang perlu mendapatkan sentuhan dari tangan profesional untuk dapat menumbuh kembangkannya.

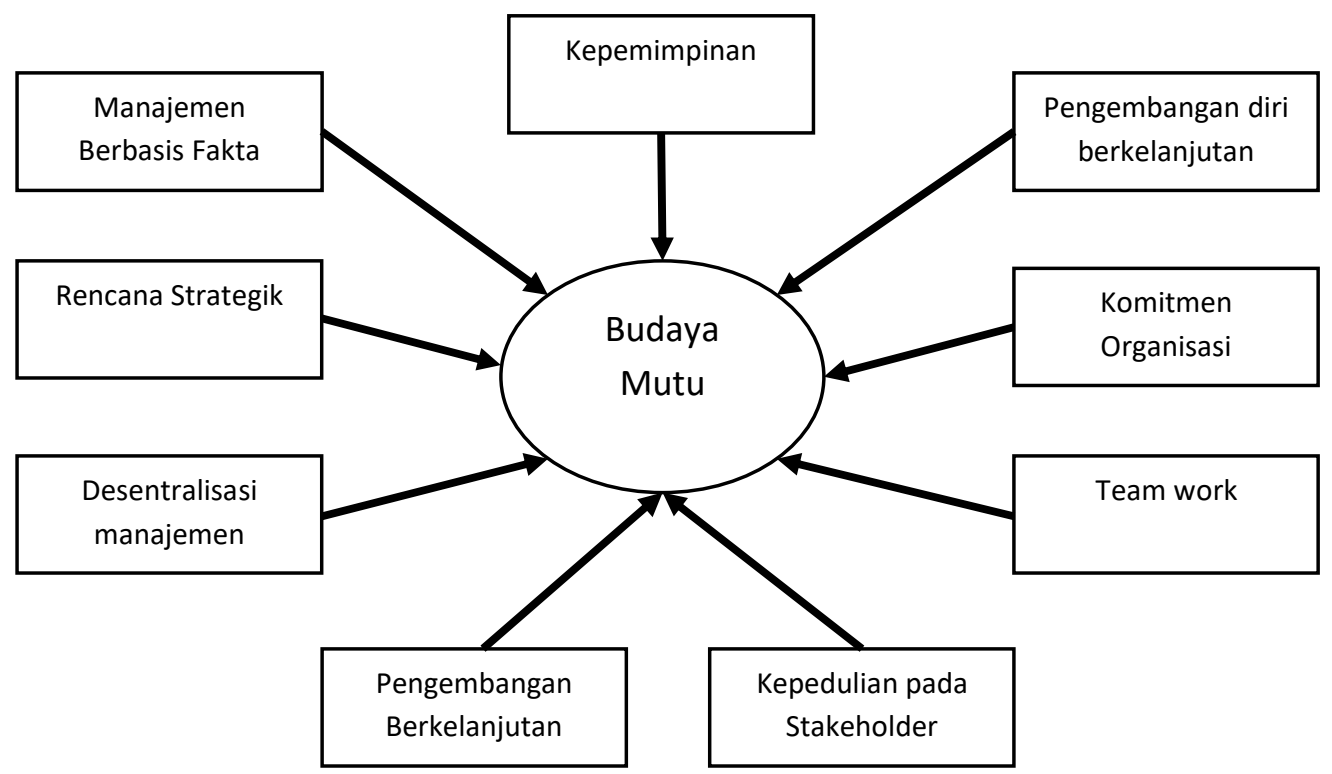

Bagan. 2 Faktor-faktor Pendorong Budaya Mutu

Hampir sama dengan pandangan atau konsep budaya mutu yang dikembangkan pada dunia Industri di atas, Pariyaporn Tungkunanan dkk menjelaskan beberapa faktor yang mendukung terciptanya budaya mutu, yaitu:

a. Kepemimpinan manajer - seorang pemimpin harus menyampaikan visi, misi dan tujuan manajemennya secara jelas sehingga memotivasi staffnya untuk bekerja dengan budaya mutu. Pemimpin juga harus mendorong staffnya untuk berinovasi dalam manajemen mutu.

${ }^{19}$ Inga Milisiunaite, Roma Adomaitiene, and Juozas Galginaitis, Quality Management As A Tool For Quality Culture Embedment: Vilnius University Approach, 31st Annual EAIR Forum in Vilnius, Lithuania 23 to 26 August 2009. p.11 
b. Manajemen berdasar fakta - manajemen yang baik seharusnya berdasar pada fakta, sehingga kita dapat membuat kebijakan secara efektif (Asaneeya Suwansirikul. 2004). Seluruh kebijakan harus dibuat secara akademis (Scientific Approach) dan logis (Tasanee Phoethisorn. 2007).

c. Perencanaan strategis - memiliki keuntungan dua dimensi sekaligus: organisasi dan anggota. Membuat rencana strategis merupakan isntrumen kunci yang dapat membantu organisasi dan anggotanya menghadapi perubahan masa depan dengan melakukan persiapan (preparation). Anggota mengetahui secara jelas tujuan organisasi dan mengambil bagian dalam membuat tujuan.

d. Desentralisasi - manajemen organisasi berbasis pada desentralisasi yang dengan demokrasi dapat mendorong staff untuk berpartisipasi dalam pembuatan keputusan. Oleh karena itu, organisasi akan memiliki fleksibilitas dalam bekerja yang berhubungan dengan ekonomi, masyarakat dan budaya. Hal ini juga dapat meningkatkan capacity-bulding untuk kesadaran diri dan pengembangan diri (self develompent) yang tetap (UNESCO, 1985).

e. Pengembangan diri berkelanjutan - Guru harus belajar selama hidupnya dan mencari pengatahuan yang dapat menyelesaikan permasalahan-permasalahan dan melakukan pengembangan pengajaran berkelanjutan dengan belajar dari perpustakaan, masyarakat dan menggunakan cendekia lokal dan pengetahuan internet untuk pengembangan diri. Mereka harus mengikuti training (pelatihan) oleh trainer guru atau pakar yang berpengalaman mengajar. Mereka harus menjalani pelatihan yang berbeda dan harus mengikuti pendidikan tinggi (pendidikan lanjut) sejalan dengan tuntutan perubahan dunia.

f. Komitmen organisasi - komitmen organisasi dapat menggambarkan kesatuan dan partisipasi dalam aktifitas berbeda yang membuat anggota sulit untuk keluar. Komitmen adalah inti dari organisasi dalam arti membuat pemahaman antara organisasi dan anggota. Anggota merupakan orang yang memiliki komitmen organisasi, dapat mewujudkan tujuan dan nilai organisasi (Decotis et. al. 1987).

g. Kerja tim - hak anggota organisasi memberi bantuan pada orang lain, berbagi pengetahuan dan memiliki kebebasan komunikasi, mereka dapat menggunakan berbagai sumber bersama secara efektif. Dengan kerjasama dalam membuat 
keputusan seperti penyelesaian masalah, anggota akan memiliki komitmen yang kuat terhadap tim, dan mereka tidak dapat menerima kegagalan tindakan (kerja). Konsekuensinya, mereka ingin bekerja dengan bermutu. Itulah mengapa kerja tim penting untuk anggota dan organisasinya (Quick. 1992).

h. Perhatian (kepedulian) pelanggan - "pengembangan tidak dapat berharga jika pelanggan tidak puas dengan perubahan itu". Permintaan tidak hanya pada saat ia membeli sebuah produk tetapi permintaannya adalah kepuasan dari penggunaan produk sampai akhir masanya. Kutipan tersebut di atas merupakan ide penting dari teori mutu. Dengan demikian, sebuah manajemen organiasai berdasarkan pada standar pelanggan atau melebihi harapannya (Banjong Jantharamat. 2001). Dapat dikatakan diamana metode pengajaran berpusat pada murid terfokus pada manfaat untuk siswa.

i. Pengembangan berkalanjutan - bertujuan untuk meningkatkan kemampuan murid yang mana merupakan kepuasaan masyarakat. Personel sekolah bekerja berdasarkan pada sebuah action plan dan investigation plan sama halnya sebuah asessment plan. Hasil penilaian dari keseluruhan proses harus dikembangkan secara berkelanjutan. ${ }^{20}$

\section{E. Dari Penjaminan Mutu ke Praktik Manajemen Mutu di Perguruan Tinggi (QM- PT)}

Merubah budaya mutu pada dasarnya dapat dilakukan dengan merubah persepsi dan sikap terhadap pengembangan mutu itu sendiri (Sommerville and Sulaiman, 1997). Merubah budaya merupakan bagian dari tujuan TQM (Pike \& Barnes, 1994) (dalam Wan Yusoff, 2006:3). Lebih lanjut, Manajemen mutu (quality management) pada lembaga pendidikan itu sendiri hakekatnya bertujuan mengintegrasikan semua fungsi organisasi yang berfokus pada pemenuhan keinginan stakeholder dan tujuan penyelenggara pendidikan sesuai tupoksi masing-masing. ${ }^{21}$ Sejalan dengan itu, QM bertujuan untuk

${ }^{20}$ Pariyaporn Tungkunanan, Punnee Leekitchwatana Narong Pimsarn and Siripun Chumnum.. Strategic plan for developing quality culture At eastern school of the office of vocational Education commission, thailand. ABAC Journal Vol. 28, No. 2 (May-August 2008, pp.5263), p.59-60

${ }^{21}$ Mursalim. Paradigma Baru Peningkatan Mutu Satuan Pendidikan Dalam Perspektif Total Quality Management. Jurnal Lentera Pendidikan, Vol. 13 No. 2 desember 2010, p.135 
mengembangkan budaya mutu (quality culture) ketika mutu dilihat sebagai tanggung jawab setiap orang.

Manajemen mutu atau yang dikenal juga dengan istilah TQM (Total Quality Management) memiliki unsur utama yang menghasilkan 4 prinsip perbaikan kualitas; kepuasan pelanggan, respek terhadap setiap orang, manajemen berdasarkan fakta, dan perbaikan berkesinambungan. selain itu, komunikasi yang effektif dengan melibatkan staff dalam pengambilan keputusan merupakan suatu hal yang sangat penting. ${ }^{22}$

Sedangkan menurut Vencent Gazpersz sepuluh unsur utama TQM menurut yaitu; fokus terhadap pelanggan (internal atau eksternal), obsesi terhadap kualitas, menggunakan pendekatan ilmiah, komitmen terhadap tujuan jangka panjang, membangun kerjasama tim, perbaikan kualitas secara berkesinambungan, pendidikan dan latihan, kebebasan terkendali, kesatuan visi, misi dan tujuan, dan keterlibatan serta pemberdayaan seluruh stakeholder pendidikan. TQM berhubungan dengan penciptaan budaya kualitas oleh pendidik dan tenaga kependidikan untuk menyenangkan atau memberi kepuasan kepada konsumen dengan dukungan organisasi. ${ }^{23}$

Secara praktis, peningkatan kualitas proses sebuah lembaga dapat dilakukan melalui metode PDCA (Plan-Do-Check-Act). Tahapan tersebut dapat digambarkan:

a. Plan, berisi penentuan proses yang mana yang perlu diperbaiki, menentukan perbaikan apa yang dipilih, dan menentukan data dan informasi yang diperlukan untuk perbaikan proses.

b. Do, berisi tentang jalannya pengumpulan data dasar tentang jalannya proses, implementasi perubahan yang dikehendaki (skala kecil), mengumpulkan data untuk mengetahui perubahan (ada perbaikan atau tidak),

c. Check, berisi langkah pemimpin untuk menafsirkan hasil implementasi (berhasil atau tidak) atau upaya pemimpin untuk memperoleh pengetahuan baru tentang proses yang berada dalam tanggung jawabnya

\footnotetext{
${ }^{22}$ Mursalim. Paradigma Baru Peningkatan Mutu Satuan Pendidikan Dalam Perspektif Total Quality Management. Jurnal Lentera Pendidikan, Vol. 13 No. 2 desember 2010, p.137

${ }^{23}$ Mursalim. Paradigma Baru Peningkatan Mutu Satuan Pendidikan Dalam Perspektif Total Quality Management. Jurnal Lentera Pendidikan, Vol. 13 No. 2 desember 2010, p.137-139
} 
d. Act, berupa pengambilan keputusan perubahan mana yang akan diimplementasikan, penyusunan prosedur baku, pelatihan ulang bagi anggota terkait, dan pemantauan secara kontinyu. ${ }^{24}$

PDA di atas perlu diimplementasikan guna meningkatkan mutu perguruan tinggi. Pengalaman menujukkan bahwa membantu mutu pengajaran guru merupakan bentuk usaha multi-level, yaitu:

a. Level institusi: desain kebijakan, dukungan pada organisasi dan sistem penjaminan mutu internal.

b. Level program; terdiri dari tindakan untuk menilai (mengukur) dan meningkatkan desain, isi dan penyampaian program kepada bagian-bagian (departeman) atau sekolah.

c. Level individu; inisiatif dapat membantu guru berprestasi berdasarkan misinya, mendorong guru berinovasi dan mendukung pengembangan pembelajaran murid dan mengambil fokus orientasi pada siswa. ${ }^{25}$

\section{F. Kesimpulan}

QA pada perguruan tinggi merupakan trend terbaru di berbagai belahan dunia. QA berkembang begitu pesat sehingga muncul istilah TQM (total quality manajemen) atau juga ada yang menyebut sebagai manajemen mutu. Dalam manajemen mutu yang menjadi perhatian serius adalah bagaimana menciptakan budaya mutu (quality culture) dalam institusi PT.

Quality Manajemen yang bertujuan menjamin terciptanya mutu, dalam aktifitasnya; menjamin mutu perencanaan (Quality Planning), mutu evaluasi (Quality Control) dan Penjaminan Mutu (Quality Assurance). Jaminan kualitas Internal Perguruan tinggi pada hakekatnya berusaha memberikan jaminan kualitas pada outcome yang dihasilkan. Jaminan tersebut diiplementasikan dalam standarisasi proses pendidikan, penelitian dan pengabdian masyarakat (Tri Dharma).

\footnotetext{
${ }^{24}$ Mursalim. Paradigma Baru Peningkatan Mutu Satuan Pendidikan Dalam Perspektif Total Quality Management. Jurnal Lentera Pendidikan, Vol. 13 No. 2 desember 2010, p.139

${ }^{25}$ Fabrice Hénard and Deborah Roseveare, 2012, Fostering Quality Teaching in Higher Education Policies and Practices An IMHE Guide for Higher Education Institutions, OECD. p.7
} 
Lulusan PT yang terjamin mutunya, diharapkan dapat diterima pada berbagai sektor. Internal Quality Assurance (Unit Penjamin Mutu PT) dan Eksternal Quality Assurance (BAN-PT) menjadi ujung tombak dalam memberikan jaminan kualitas pada stakeholder penerima manfaat PT, baik orang tua mahasiswa yang terpenting lagi adalah pasar dunia kerja baik dalam negeri maupun luar negeri. 


\section{Daftar Pustaka}

, diakses tanggal 15 Maret 2014 dari www.ranking-

ptai.info/ranking/skor_akreditasi_ptain.php

, www.ranking-ptai.info/ranking/skor_akreditasi_ptain.php Diakses tanggal 15 Maret 2014.

Andreawilger. 1997. Quality Assurance In Higher Education: A Literature Review.

National Center For Postsecondary Improvement 508 Ceras School Of Education

Stanford University, Stanford, Ca 94305-3084.

Archibong, Florence Imaobong. Instructional Supervision In The Administration of

Secondary Education: A Panacea For Quality Assurance. European Scientific

Journal, June Edition Vol. 8, No.13, ISSN: 1857 - 7881 (Print) E - ISSN 1857- 7431.

Archibong, Ijeoma A.. Strengthening Internal Quality Assurance for Improved Education

Delivery in Nigerian Public Universities. Research on Humanities and Social

Sciences ISSN 2222-1719 (Paper) ISSN 2222-2863 (Online) Vol.3, No.1, 2013

www.iiste.org (172-177). P-173

Becker, Gary S. 1993. Human Capital A Theoretical and Empirical Analysis with Special Rference to Education Third Edition. The University of Chicago Press: Chicago London. P.17

Direktorat Jenderal Pendidikan Tinggi Departemen Pendidikan Nasional, 2006. Panduan Pelaksanaan Sistem Penjaminan Mutu Perguruan Tinggi (SPM-PT), hal.4

Haris, Ikhfan. 2013. Assessment On The Implementation Of Internal Quality Assurance At Higher Education (An Indonesian Report). Journal Of Educational And Instructional Studies In The World, November 2013, Volume: 3 Issue: 4 Article: 06 Issn: 2146-7463 (P. 41-50). P.41-42

Hénard, Fabrice, Deborah Roseveare, 2012, Fostering Quality Teaching in Higher Education Policies and Practices An IMHE Guide for Higher Education Institutions, OECD.

Kleijnen, Joannes Chrysostomus Bernardus Marie. 2012. Internal quality management and organisational values in higher education Conceptions and perceptions of teaching staff. Jan Kleijnen, Maastricht 2012 Production: Datawyse | Universitaire Pers Maastricht. 
LiHong, Liu, 2008, QUALITY ASSURANCE : Internal Strategies in US Higher Education Institutions - A Case Study at the University of Nebraska - Lincoln, National Academy of Education Administration Beijing, P.R. China.

Lodico, Marguerite G., Dean T. Spaulding, Katherine H. Voegtle. 2006. Methods In Educational Research From Theory to Practice.( John Wiley \& Sons, Inc: San Francisco, CA 94103-1741)

Milisiunaite, Inga, Roma Adomaitiene, and Juozas Galginaitis, Quality Management As A Tool For Quality Culture Embedment: Vilnius University Approach, 31 st Annual EAIR Forum in Vilnius, Lithuania 23 to 26 August 2009

Mursalim. Paradigma Baru Peningkatan Mutu Satuan Pendidikan Dalam Perspektif Total Quality Management. Jurnal Lentera Pendidikan, Vol. 13 No. 2desember 2010

Pariyaporn Tungkunanan, Punnee Leekitchwatana Narong Pimsarn and Siripun Chumnum.. Strategic plan for developing quality culture At eastern school of the office of vocational Education commission, thailand. ABAC Journal Vol. 28, No. 2 (May-August 2008, pp.52-63)

Sadler, D. Royce. Assessment, Evaluation And Quality Assurance: Implications For Integrity In Reporting Academic Achievement In Higher Education. Education Inquiry Vol. 3, No. 2, June 2012, p.204

Sallis, Edward. Alih Bahasa Ali riyadi, Ahmad \& Fahrurozi. 2006. Total Quality Management in Education: Manajemen Mutu Pendidikan. Yogyakarta.

Tongsamsi, Isara, Akom Chaikeaw, Chidchanok Churngchow, \& Thoedtida Thipparat, A Structural Equation Model of Factors Influencing the Quality Culture of the Workforce in Thailand Public Higher Education Institutions, International Journal of Education ISSN 1948-5476 2012, Vol. 4, No. 4, www.macrothink.org/ije.

Usman, Husaini. 2009.Manajemen : Teori, Praktik, dan Riset Pendidikan. Jakarta: Bumi Aksara.

Wan Yusoff Wan Mahmood, Abdul Hakim Mohammed, Mohd. Saidin Misnan, Zakaria Mohd. Yusof, Ahmadon Bakri, Development Of Quality Culture In The Construction Industry. Universiti Teknologi Malaysia, UTM Skudai 81310, Johor, Malaysia, 4-7

Yadav, Harpal Singh, Quality culture in Teacher Education. International Indexed \& Refferred Research Journal, ISSN-2250-2599; Vol. I* ISSUE -1 Oct., 2012 